\title{
Awareness Regarding Sex Knowledge Among Adolescent Girls (16-20 Years)
}

\author{
Nirojini Bhat Bhan, Payal Mahajan and Minal Sondhi
}

\section{INTRODUCTION}

Adolescence is the invention of technological, industrial society that is marked by a discontinuity between childhood and adulthood. (Saraswati, 1999). World health Organization (WHO) has defined adolescence as the age of 10 to 19 years. It is characterized by physical, psychological and social change transformation and maturation that takes place during this period. It is also called as period of stress and storm, a period when society sends mixed signals to its youngsters which results in confusion, frustration, despair and risk taking behavior. Young people want to see guidance but do not know from where to get it.

Sex education perhaps helps in preparing young adolescents to have responsible attitudes and behaviour towards sex for a harmonious sexual life. Sex knowledge is the inculcation of the moral attitude towards sex instincts. It also dispels many myths and superstitions and clarifies the various terms of sexuality. As a study conducted by National Family Health Survey (1992-1993) indicates that there were around $12 \%$ spontaneous abortions among girls in the age group of 13-14 years with almost no induced abortions, whereas in the age group 15-19years, there were $7.3 \%$ spontaneous abortions and $1.7 \%$ induced abortions. Besides poor access to contraception and contraceptive failure, lack of information or misinformation regarding reproduction as also the incidence of rape, contribute to the high rate of abortions amongst adolescents.

\section{PURPOSE OF THE STUDY}

Most parents do not discuss topics related to sexual issues. As a result, many teens turn to peers and media for related information which leads to inaccurate information with jumbled and often provide contradictory messages regarding sex and other related issues. Sex education is required for adolescents to provide them positive direction, right information which would avoid unnecessary worries and tensions. For example, many young girls without proper knowledge about menstru-ation are shocked to find themselves bleeding during that phase. Parents and teachers have to be very tactful so that girls do not obtain wrong information. Misconceptions lead to teenage pregnancies outside marriage which are rising in India. Parents often blame the perverse influence of cinema and counsellors blame ignorance.

Adolescents who receive the related information from books or sex educators have information superior in quality to that of their peers and they usually feel more satisfied with it.

\section{METHODOLOGY}

The sample for the study consisted of 75 adolescent girls in the age group of 16-20 years from 3 different educational institutes of Pathankot city (Punjab). Purposive sampling technique was used for the selection of sample.

For data collection pre-tested interview schedule was used to know the level of sex information among adolescent girls. Interview schedule consisted of 2 major parts-(i) General information, which consisted of questions like name, age, educational qualification, type of family etc.; (ii) Specific information regarding menarche, homosexuality, heterosexuality, STDs, birth control devices, etc.

After the collection of data, the procedure of content analysis was adopted, coding was done on the basis of categories.

\section{RESULTS}

The results of the present study reveal that $46.6 \%$ of the total sample were in the age group of $16-18$ years and were studying in $10^{\text {th }}$ to $12^{\text {th }}$ standard. The rest $53.4 \%$ were in the age group of 18-20 years and were doing graduation with different subjects like medical (22\%), nonmedical (18\%), commerce (12\%) and arts (48\%).

Menarche: It has been seen that majority of the sample $(76 \%)$ experience menarche at the 
age of 12-14 years. As, a study conducted by Mussen (1990) revealed that during the past 5 to 10 decades, youngsters have reached puberty progressively earlier.

Table 1 show that $100 \%$ of the sample had noticed changes in their body during puberty, like increase in their height and weight, growth of pubic hair and enlargement of breasts.

Table 1: Changes in body after menarche

\begin{tabular}{lcc}
\hline Bodily changes & No. of girls & $\%$ \\
\hline Increase in height and weight & 75 & 100 \\
Growth of pubic hair & 75 & 100 \\
Enlargement of breasts & 75 & 100 \\
\hline
\end{tabular}

Table 2 reveals that majority of the girls $(37.33 \%)$ were aggressive in their behaviour and fearful $(34.67 \%)$ because they were not mentally prepared for these bodily changes. $22.66 \%$ of the total sample showed cranky behaviour on the onset of menarche and showed tantrums

Table 2: Emotional changes related to menarche

\begin{tabular}{|c|c|c|c|c|c|c|}
\hline \multirow{2}{*}{$\begin{array}{l}\text { Emotional } \\
\text { changes in } \\
\text { behavior }\end{array}$} & \multicolumn{2}{|c|}{ Sometimes } & \multicolumn{2}{|c|}{ Neutral } & \multicolumn{2}{|c|}{ Often } \\
\hline & No. & $(\%)$ & No. & $\%$ & No. & $(\%)$ \\
\hline $\begin{array}{l}\text { Aggressive } \\
\text { Behavior }\end{array}$ & 28 & (37.33) & $42^{*}$ & (56.00) & - & $(0.0)$ \\
\hline $\begin{array}{l}\text { Cranky } \\
\text { Behavior }\end{array}$ & 17 & (22.66) & $43^{*}$ & (57.33) & - & $(0.0)$ \\
\hline $\begin{array}{l}\text { Fearful } \\
\text { Behavior }\end{array}$ & 26 & (34.67) & $24 *$ & (32.00) & - & $(0.0)$ \\
\hline $\begin{array}{l}\text { Throwing } \\
\text { Temper }\end{array}$ & 04 & (5.33) & $42^{*}$ & (56.00) & - & $(0.0)$ \\
\hline
\end{tabular}

* Multiple responses.

Table 3: Social interaction

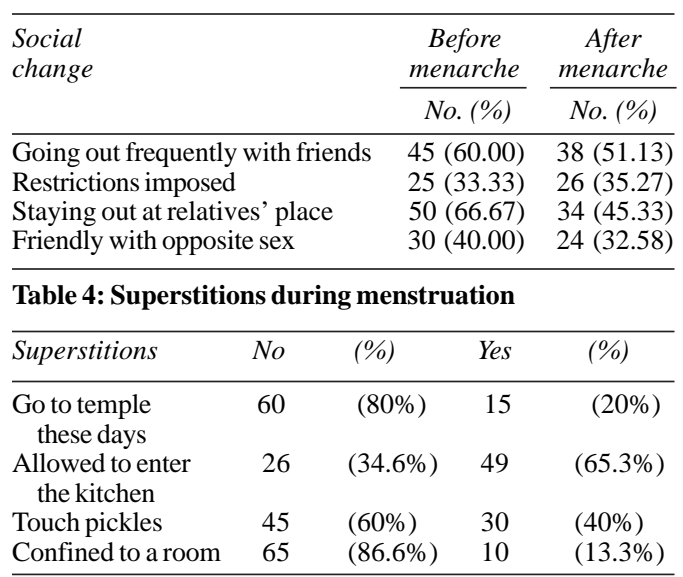

occasionally $(5.33 \%)$.

Table 3 reveals that majority of the sample were imposed restrictions (social interaction) after the on set of menarche where as not much of restrictions were imposed before the onset of menarche

It is evident from the table 4 that majority (more than 50\%) of the sample were from superstitious family as they were confined to their rooms; were not allowed to have physical contacts with their family members and were not allowed to enter their Puja rooms during their periods (menstruation).

It is clear from table 5 that majority of the sample were unaware regarding the terms Masturbation, Homosexuality and Heterosexuality and held negative(-ve) attitude them. Only few $\%$ of the sample were aware of these terms and showed positive (+ve) attitude.

Table 6 shows that $80 \%$ of the sample was in favor of having prior knowledge regarding sex (both for boys \& girls) as they have to enter into married life sooner or late. Also they were asked about the terms -STD/HIV and birth control devices and it was found that majority of them had prior knowledge regarding these terms as they had different sources of information.

Table 7 reveals that the major source of information of; majority of the respondents regarding menstruation was mother; majority of the respondents were unaware about the terms masturbation and homosexuality and few of them knew about it through magazines, peers and cousins; more than $50 \%$ of the sample were aware of the terms STD/HIV and birth control methods through various sources but the major source was mass-media (Television).

Hence, it is clear from the above information that majority of the sample had poor level of sex

Table 5: Awareness and attitude regarding masturbation, homosexuality and heterosexuality

\begin{tabular}{llll}
\hline Terms & Aware & Unaware & Attitude \\
\hline Masturbation & $15(20 \%)$ & $60(80 \%)$ & $-\mathrm{ve}$ \\
Homosexuality & $15(20 \%)$ & $60(80 \%)$ & $-\mathrm{ve}$ \\
Heterosexuality & $17(22.6 \%)$ & $58(77.3 \%)$ & $-\mathrm{ve}$
\end{tabular}

Table 6: Attitude towards prior knowledge regarding sex education

\begin{tabular}{lcc}
\hline Options & No. of girls & $\%$ \\
\hline +ve (positive) & 60 & $80 \%$ \\
-ve (negative) & 15 & $20 \%$ \\
\hline
\end{tabular}


Table 7: Sources of information

\begin{tabular}{lccccccc}
\hline & Mother & Peers & Mass-Media & School & Cousins & Magazines & No knowledge \\
\hline Menstruation & 34 & 15 & 1 & 10 & 15 & - & - \\
& $(45.3 \%)$ & $(4 \%)$ & $(1.3 \%)$ & $(13.3 \%)$ & $(4 \%)$ & - & - \\
Masturbation & - & 4 & - & - & 2 & 10 & 59 \\
Homosexuality & - & $(80 \%)$ & - & - & $(2.6 \%)$ & $(13.3 \%)$ & $(78.66 \%)$ \\
STD/HIV & - & $(9.33 \%)$ & - & - & - & 17 & 51 \\
& - & $(1.3 \%)$ & $(56 \%)$ & $(13.3 \%)$ & - & - & 22 \\
Birth Control & 2 & 15 & 50 & - & - & 6 & $(29.33 \%)$ \\
& $(2.6 \%)$ & $(20 \%)$ & $(66.6 \%)$ & & & $(8 \%)$ & $(2.6 \%)$ \\
\hline
\end{tabular}

knowledge and those who was aware received sex knowledge vastly from peer groups and mass media where as parents and schools were found to be salient regarding imparting sex education to their children.

\section{DISCUSSION}

The results of the study revealed that girls had poor level of sex knowledge. Although girls knew about certain topics but were hesitant to talk about them. Reviewing the literature available regarding awareness level of adolescents towards sex related issues (Kumar,1995; Bernard,1988; Francis, 1997; Family Planning Association of India, 1994), it is found that majority of the adolescents were aware of certain aspects of sex education as HIV, AIDS, Menarche, but not much of it. They also had few misconceptions. Level of knowledge among females was below average. Further findings reveal that it is all due to lack of sources of correct information on sex. A matter of serious concern was a fact that the students had no reliable means of obtaining correct information. Schools were inadequately equipped to meet the challenge. So they should be provided with unbiased, unmoralistic information so that they are better informed and better adjusted to their changing physical, biological and emotional needs.

KEYWORDS Sex Knowledge. Adolescents. Awareness. Aids. Homosexuality. Heterosexuality

ABSTRACT The present study aim to know the level of sex knowledge among adolescent girls in the age group of 16 to 20 years. The sample consisted of 75 adolescent girls from 3 different educational institutes of Pathankot city (Punjab). Purposive sampling technique was used to select the sample. Interview schedule was used for the collection of the data. The information was collected from the respondents related to menarche, masturbation, homosexuality, heterosexuality and source of information. The results of this study revealed that the girls had poor level of sex knowledge. Though girls knew about certain topics but were hesitant to talk about them.

\section{REFERENCES}

Bernard, J.J. and Susan, M.S.: Study on Men and Women of Reproductive Ages to Determine Their Existing Knowledge Regarding AIDS. American Journal of Public Health, I (81): 53-58 (1988).

Chaube, S.P.: Adolescent Psychology.Vikas Publishing House, New Delhi (1983).

Family Planning Association of India: Youth Sexuality: A Study of Knowledge, Attitudes, Beliefs and Practices Among Urban Educated Indian Youth.1993-94. Family Planning Association of India, Sex Education Counseling Research and Training/Therapy (1994).

Francis, P.T., Gill, J.S. and Choudhary, S.: Knowledge, Beliefs and Attitudes Regarding AIDS, STDs and human sexuality among Sr. Sec. students in Delhi. Pp. 162-165 In: O.P. Aggarwal, A.K. Sharma, and A. Indrayan (Eds.): HIV AIDS Research In India. Pp. NACO, Ministry of Health and Family Welfare, New Delhi (1997).

Kumar, A., Lal, P., Walia, M., Arora, R. and Gulati, N. (1995). Awareness Regarding AIDS. Journal of Communicable Diseases, 28 (1): 20-27 (1995).

Ministry of Health and Family Welfare: India. Country Paper for South Asia Conference on Family Life Education (18-19Nov) New Delhi, 21-23 July, 1998 (1998).

National Convention on Family Life Education: Emerging Challenges. A report published by National Institute of Public Cooperation and Child Development, New Delhi (1998).

Samkaria, M.: Attitudes of Parents, Teachers and Adolescents Towards Family Life Education: A Comparative Study of Jammu and Palampur. Unpublished Dissertation, P.G.Deptt. of Home Science, University of Jammu, Jammu (2000).

Saraswati, T.S.: Culture, Socialization and Human Development. Sage Publications, New Delhi (1999).

Thapar, V.: Background paper presented in the National Convention on Family Life Education (18-19Nov), pp16. NIPCCD, New Delhi (1998).

Authors' Address: Nirojini Bhatt Bhan, Payal Mahajan and Minal Sondhi, P. G. Department of Home Science, University of Jammu, Jammu 180 006, Jammu and Kashmir, India 